\title{
PENDEKATAN EXTREME PROGRAMMING MODEL PADA PERANCANGAN APLIKASI MENGGUNAKAN UML
}

\author{
${ }^{1}$ Komang Yudhistira, ${ }^{2}$ Sita Muharni, ${ }^{3}$ Usep Saprudin \\ ${ }^{1}$ Komang Yudhistira, STMIK Dharma Wacana, komanngyudhistira9@gmail.com \\ ${ }^{2}$ Sita Muharni, STMIK Dharma Wacana, sita.stmikdcckotabumi@gmail.com \\ ${ }^{3}$ Usep Saprudin, STMIK Dharma Wacana, Usepdharmawacana@gmail.com \\ Jalan Kenangan No.3 Mulyojati Kota Metro
}

\begin{abstract}
ABSTRAK
Extreme Programming merupakan proses rekayasa perangkat lunak yang cenderung menggunkan pendekatan berorintasi objek. Metode Extreme Programming ini memberikan keselarasan terhadap perubahan-perubahan dari sisi desain dan fitur dengan penanganan secara fleksibel. Pada tahapan desainya peneliti ini akan menggunakan UML (Unified Modelling Language). Dalam desain UML menggunakan Use Case Diagram, Activity Diagram, dan Sequence Diagram. Hasil penelitian ini akan menjadi dasar dalam membangun aplikasi mobile yang nantinya menjadi alat bantu penghapalan mantra.
\end{abstract}

Kata Kunci : Aplikasi, Extreme Programming, UML(Unified Modelling Language).

\section{PENDAhuluan}

\section{Latar Belakang Masalah}

Menurut Prabowo dalam (Supriyatna, 2018) Extreme Programming (XP) merupakan proses rekayasa perangkat lunak yang cenderung menggunkan pendekatan berorintasi objek dan sasaran dari metode ini juga sesuai jika tim dihadapkan dengan requirement yang tidak jelas maupun terjadi perubahan-perubahan requirement yang sangat cepat.

Aplikasi yang dibangun dengan metode Extreme Programming adalah aplikasi mobile berbasis android. Metode Extreme Programming ini memberikan keselarasan terhadap perubahan-perubahan dari sisi desain dan fitur dengan penanganan secara fleksibel maka dari itu dibuatlah sebuah aplikasi mobile yang nantinya menjadi alat bantu penghapalan mantra.

Pada tahapan desainya peneliti ini akan menggunakan UML (Unified Modelling Language). Untuk membangun aplikasi mobile berbasis android.

\section{Metode Penelitian}

Metode pengembangan yang digunakan dalam penelitian ini adalah metode Extreme Programming yang ditunjukan pada gambar 1 berikut.

\subsection{Planning}

A. Kebutuhan fungsional

Aplikasi ini menjadi alat bantu penghapalan mantra umat hindu sehari-hari.

B. Kebutuhan Non Fungsional

1. Aplikasi bisa diakses lewat android

2. Aplikasi ini dapat menampilkan audio dan video mantra hindu.

3. Aplikasi menampilkan teks mantra

4. Pengguna bisa mendengar suara mantra.

\subsection{Design}

Pada tahap ini peneliti membuat tampilan use case diagram, activity diagram, squence diagram tentang aplikasi mobile berbasis android, mulai dari menu, penambahan alternatif, dan lainnya, Lalu peneliti membuat algoritma program tersebut. Pada perancangan sistem nya menggunakan UML (Unified Modelling Languange).

\subsection{Coding}

Pada tahap ini menerapkan design model kedalam program aplikasi dengan menggunakan android studio. Bahasa pemrograman JDK (Java Development Kit) 


\subsection{Testing}

Pada tahap ini dilakukan uji coba terhadap aplikasi agar dapat digunakan tanpa menemukan kendala-kendala apapun. Adapun uji coba yang akan dilakukan menggunakan metode blackbox. Pengujian secara blackbox merupakan pendekatan menguji apakah setiap fungsi didalam program dapat berjalan dengan benar.

\section{HASIL DAN PEMBAHASAN}

\subsection{Usecase Diagram}

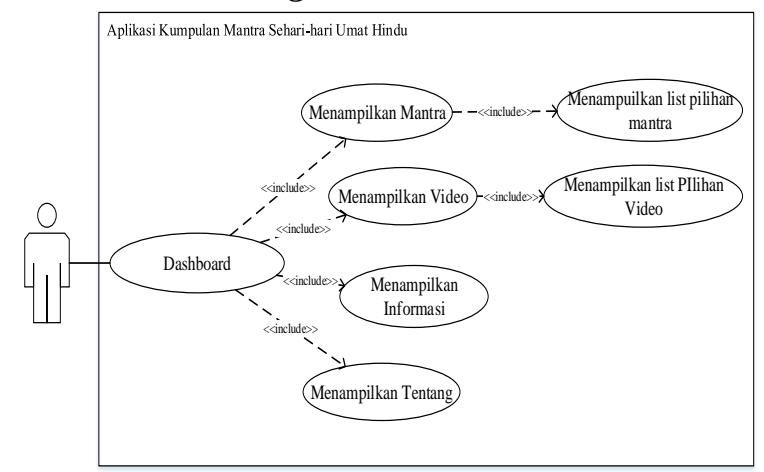

Gambar 2 Use Case Diagram.

\subsection{Activity Diagram}

a. Activity Diagram Memilih dan Memutar Mantra.

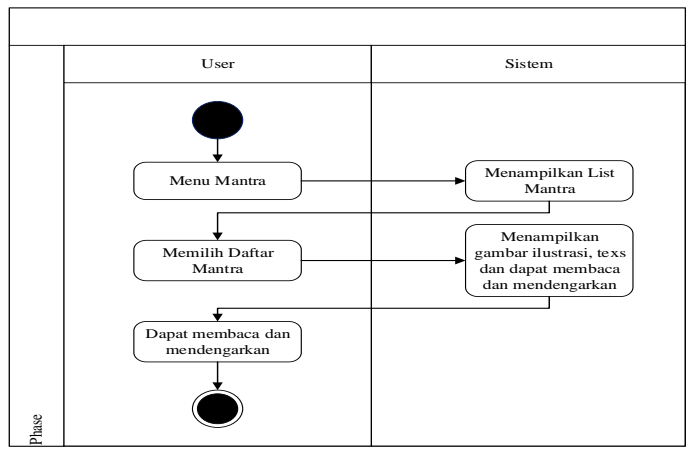

Gambar 3 Activity Diagram Memilih dan Memutar Mantra.

b Activity Diagram Melihat Video.

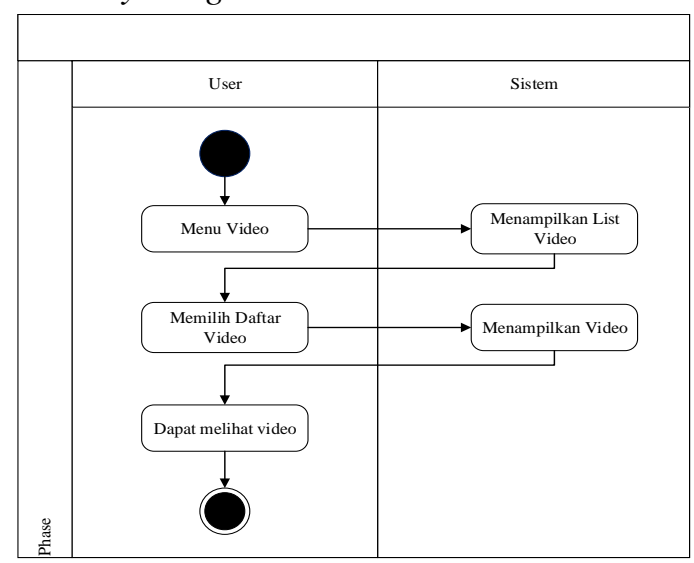

Gambar 4 Activ ity Diagram Melihat Video.
C Activity Diagram Melihat Informasi Pengucapan Mantra.

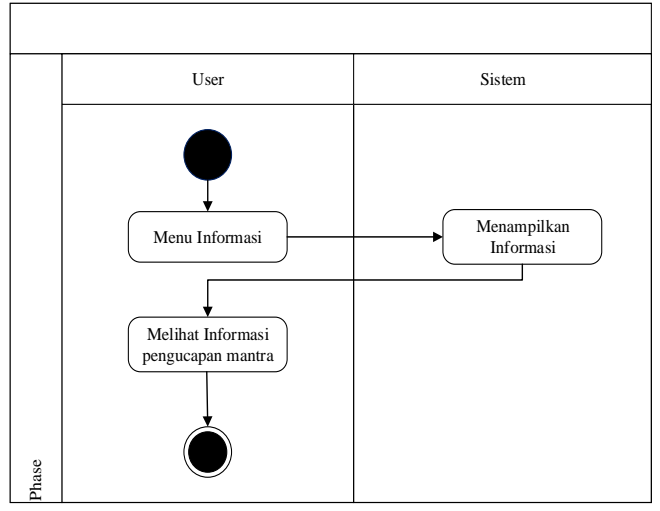

Gambar 5 Activity Diagram Melihat Informasi Pengucapan Mantra.

d Activity Diagram Melihat Version Aplikasi

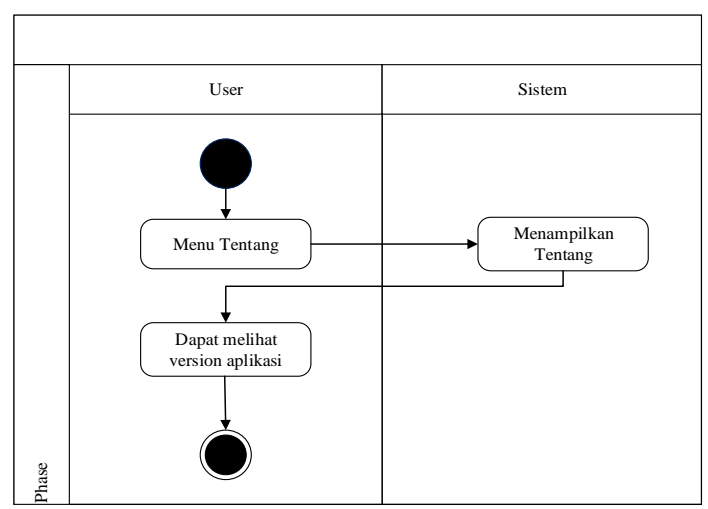

Gambar 6 Activity Diagram Melihat Version Aplikasi

\subsection{Sequence Diagram}

a Sequence Diagram Memilih dan Memutar Mantra.

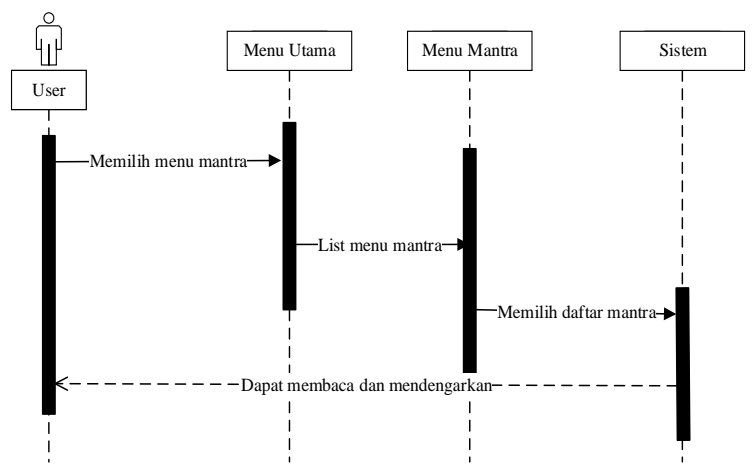

Gambar 7 Sequence Menu Diagram Memilih dan Memutar 
b Sequence Diagram Melihat Video.

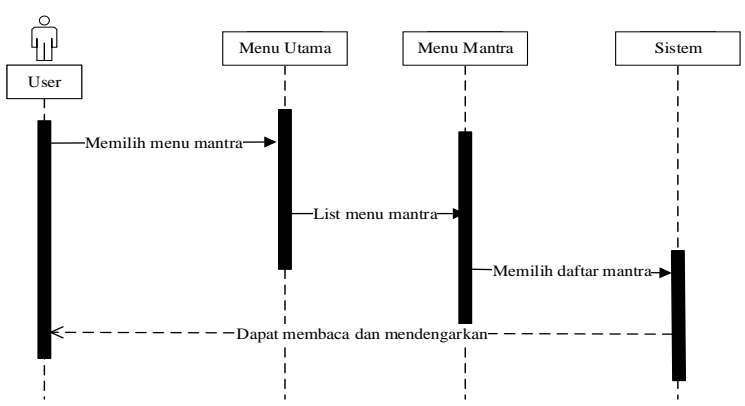

Gambar 8 Sequence Menu Melihat Video.

c Sequence Diagram Melihat Informasi Pengucapan Mantra.

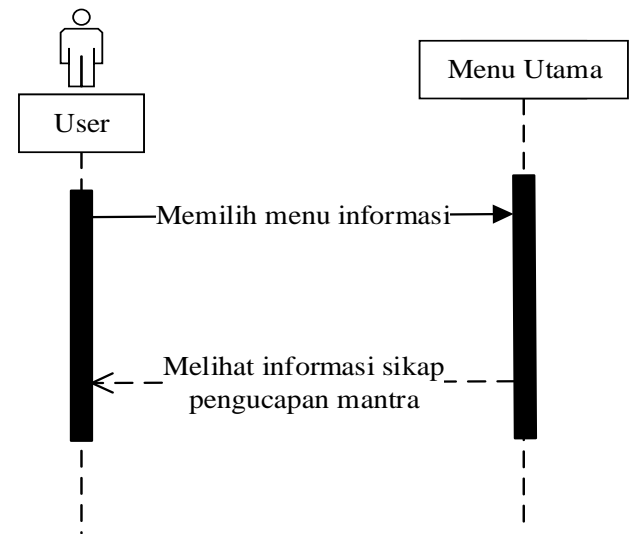

Gambar 9 Sequence Diagram Melihat Informasi Pengucapan Mantra.

d. Sequence Diagram Melihat Version Aplikasi.

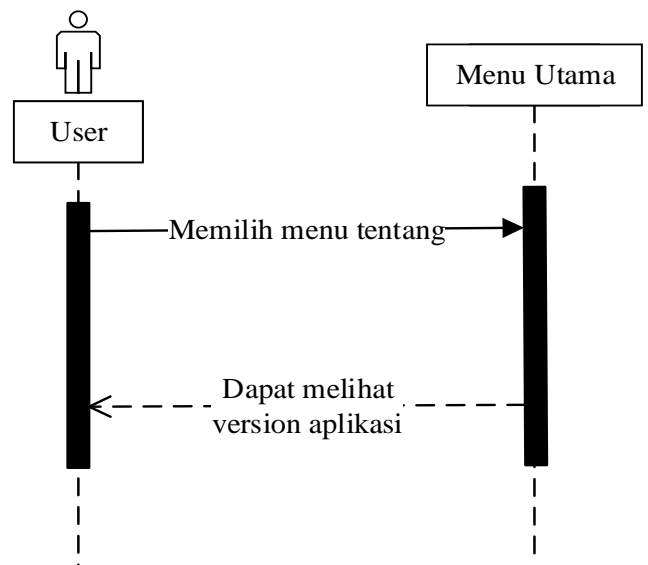

Gambar 10 Sequence Diagram Version Aplikasi.

\section{KESIMPULAN DAN SARAN}

\subsection{KESIMPULAN}

Kesimpulan yang dapat diambil dari penelitian ini yaitu bahwa aplikasi ini menggunakan pendekatan metode XP model dalam membangun aplikasi mobile berbasis android yang nantinya menjadi alat bantu penghapalan mantra.

\subsection{SARAN}

Berdasarkan kesimpulan di atas, maka terdapat beberapa saran yaitu diharapkan pengembangan aplikasi ini agar menjadi lebih baik lagi di masa depan.

\section{DAFTAR PUSTAKA}

B. A. Candra, K. Muludi, A. R.Irawati, "Rancang Bangun Sistem Informasi Manajemen Terpadu (SIMANTEP) Online PT. PLN (Persero) Sektor Pembangkitan Tarahan Lampung Dengan Metode Exttreme Programming”, Jurnal Komputasi, Vol. 1, No. 1,2012

Hakim, Rachmad, dan Sutarto, 2009, Mastering Java. Jakarta : Media Komputindo

Hermawan, Stephanus S. 2011. Mudah Membuat Aplikasi Android. Yogyakarta: C.V Andi

Laboraturium Rekayasa Perangkat Lunak. 2013. Extreme Programming. TeknikInformatika, FTIF, ITS. (diakses 17 Oktober 2017, link: http://rpl.if.its.ac.id/extremeprogramming//)

Lubis, B. O (2016). Penerapan Global Extreme Programming Pada Siste Informasi Workshop, Seminar Dan Pelatihan Di Lembaga Edukasi. Jurnal Informatika, 3(2),234-246. Retrieved from http://ejurnal/index.php/ji/articel/view/105 5

Ladjamudin , Al BahraBin, 2006. Rekayasa Perangkat Lunak, Yogyakarta: Graha Ilmu.

Mustaqbal, M . Sidi, Roero Fajri Firdaus, Hendra Rahmadi 2015. Pengujian Aplikasi 
Menggunakan Black Box Testing Boundary Value Analiysis Jurnal Ilmiah Teknologi Informasi Terapan Vol.1.No.3.

Nidhra, Srinivas dan Jagruthi Dondeti. 2012. Black box and White box Testing Techriques - A Literature Review. International Journa of Embedded Systeam and Application (IJESA) Vol 2, No.2.

R. Ferdiana,"Rekayasa Perangkat Lunak yang Dinamis dengan Global Etreme Programming",Yogyakarta, Andi,2012.

Soetam, Rizkiy. 2011 "Konsep Dasar Rekayasa Perangkat Lunak". Jakarta: Prestasi Pustaka.

U. Ependi, Q. Widiyanti "Rancang Bangun Aplikasi Kamus Istilah Akutansi Pada Smartphone Dengan Metode Extreme Programming, STMIK AMIKOM yogyakarta, 2014

Widhiartha, Putu, 2008. Etreme ProgreammingMelakukan Pengembangan Perangkat Lunak Dengan Lebih Sederhana.www.ilmukomputer.org.

Widodo. 2008. Extreme Programming: Pengembangan Perangkat Lunak Semi Formal. Falkutas Teknik Universitas Negri Jakarta. e-Indonesia Initiative 2008 (Eii2008).

Supriyatna, A. (2018). Metode Extreme Programing Pada Pembangunan web Aplikasi Seleksi Peserta Pelatihan Kerja. Jurnal Teknik Informatika, 11(1),118.http://doi.org/10.15408/jti.v11i1.6628

Timbowo, Deify. 2016. Manfaat Penggunaan Smartphone Sebagai Media 2.2. Komunikasi. Fakultas Ilmu Sosial dan Politik Universitas Sam Ratulangi.

Rahmi Raisya, Perdana sari, Rika, dan Suhatman, Rahmat. Pendekatan Metodologi Extreme Programming Pada Aplikasi E-commerce (Studi Kasus Sistem Informasi Penjualan Alat-alat Telekomunikasi). Junal Komputer Terapan Vol.2,No, November 2016, 83-92. Politeknik Caltex Riau
Y. I. Chandra, "Perancang Aplikasi Resep Makanan Tradisional Indonesia Menggunakan Pendekatan Aglie Process Dengan Model Etreme Programming Bebasis Android “, Seminar Nasional APTIKOM(SEMINASTIKOM), 2016 